\title{
Innovation diffusion in tourism: how information about blockchain is exchanged and characterized on twitter
}

\author{
Francesco Bolici \\ Department of Economics and Law, University of Cassino, Cassino, Italy \\ Chiara Acciarini \\ Department of Business and Management, Luiss University, Rome, Italy \\ Lucia Marchegiani \\ Department of Business Studies, ROMA TRE University, Roma, Italy, and \\ Luca Pirolo \\ Department of Business and Management, Luiss University, Rome, Italy
}

Innovation diffusion in tourism
Received 31 January 2020 Revised 21 April 2020 Accepted 6 June 2020

\begin{abstract}
Purpose - Technological innovations provide huge opportunities to expand and revolutionize the scope of products and services offered. This is particularly true for tourism, which is undergoing significant changes due to the development of new technologies. The level of technology diffusion depends on several factors like the exchange of information among peers, and the attitude and shared perception among the contributors. The aim of the study is to explore the diffusion of technology in tourism with a specific focus on the social media discourse around new technologies. Thus, the paper investigates the level of interest in these new technologies analysing the information exchange occurring between individuals on Twitter in order to explore the influence of reciprocal networking.

Design/methodology/approach - To capture the attitudes expressed in the industry, the study analyses the ongoing discourse on Twitter as a proxy for the participants "interest in new technologies. Through a social network analysis of the tweets and retweets conducted over a period of nine months, the research maps the level of information exchange about the diffusion of new technologies. Moreover, the sentiment analysis provides an interesting overview of the individuals" attitudes towards the awareness or the adoption of new technologies. Findings - Our analysis has provided several insights: (1) the information network on blockchain in tourism consists of participants who change very quickly over time (high turnover of accounts); (2) some contributors have an extremely important role in influencing the flow of information in the system (information centralization), they can have a generalist (discussing several topics) or a specialist (focusing on a specific topic) behaviour and this strategic choice influences their network's structure; (3) these central nodes also have an impact on the definition of positive and negative sentiment towards a topic (sentiment influencer).

Research limitations/implications - The paper contributes to the literature on technology diffusion, by focusing on one of the preconditions of diffusion that is the shared positive attitude towards technological innovation. More specifically, we adopt a network-based approach, which is useful to explain the level of information exchange and the public discourse that can impact the shared perception and attitude towards technological innovation. The study also highlights the role of knowledge brokers in influencing this public discourse. Future studies can deepen the association between positive perception, higher levels of information exchange and increasing usage of specific technologies. Our results also suggest further exploring the opportunity to combine social media data and other sources of information to shed more light on the technological innovation diffusion processes.
\end{abstract}

(C) Francesco Bolici, Chiara Acciarini, Lucia Marchegiani and Luca Pirolo. Published by Emerald Publishing Limited. This article is published under the Creative Commons Attribution (CC BY 4.0) licence. Anyone may reproduce, distribute, translate and create derivative works of this article (for both commercial and non-commercial purposes), subject to full attribution to the original publication and authors. The full terms of this licence may be seen at http://creativecommons.org/licences/by/4.0/ legalcode

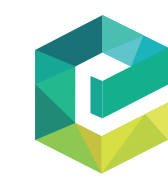

The TQM Journa Emerald Publishing Limited $1754-2731$
$-2020-0016$ 
Practical implications - This paper shows how practitioners can benefit from the analysis of information exchange about new technologies in tourism adopting a network perspective with the aim of understanding the level of influence among contributors. Moreover, the increasing interest in blockchain technology and the potential combination between social media data and other sources of information can offer promising insights. Social implications - The present study explores the level of technology diffusion through the analysis of information exchange on social media (Twitter). Furthermore, the dynamics of individual user behaviour offers a better understanding about media effects.

Originality/value - While previous research is focused on the users' perception towards the development of new technologies in tourism, the aim of this study is to investigate the dynamics behind the level of diffusion of information and awareness about these new technologies, which still represents an unexplored area of research.

Keywords Social network analysis, Tourism, Blockchain, Technology adoption, Technology diffusion, Perception, Social media, Bitcoin

Paper type Research paper

\section{Introduction}

Tourism is a global driver of growth that leads to the reduction of poverty and to the promotion of socio-economic development. Recently, the World Travel and Tourism Council stated that the global tourism industry grew by $3.9 \%$ in 2018 , creating around 320 million jobs in the world economy. Furthermore, the sector generated $10.4 \%$ of worldwide economic activity in 2018. Nowadays, tourism is undergoing significant changes and new business models are emerging within the sector: for example, the online travel service bookings increased rapidly by $230 \%$ from 2015 to 2016 with the highest amount of revenue generated in the United States with $\$ 93.7$ billion in 2018, followed by Europe with $\$ 92.3$ billion of revenue in the same year (Statista, 2019).

The main transformations of the sector are enabled by the digitalization phenomenon and are largely linked to the diffusion of big data, the rise of platform economy and artificial intelligence and to the improvement of the customer experience [1]. On the one hand, the improvement of an online presence, the enhancement of interactions and the development of networking structures as well as digital collaborations are the main reasons for digitizing business. On the other hand, the major obstacles in implementing digital technologies within the tourism industry are the lack of financing, the presence of high training costs and the rapid technological changes (Dredge et al., 2018).

The evolution of new technologies, like cloud computing, wearable devices and mobile tools, creates many opportunities, but also several challenges. First and foremost, the digitalization of the industry supports the growth of online transactions and service activities; in addition, the interconnectedness between physical and digital worlds facilitates data exchanges and improves the communication between the parties. One of the main technological innovations that will reshape the future of tourism is blockchain technology and its numerous applications, such as the use of digital currencies (e.g. bitcoin), the creation of smart contracts, the implementation for public services, the management of digital and sales, the tracking of records, the automation of supply systems and the development of apps (Nam et al., 2019).

Although a wealth of reports shows a promising trend of technological innovation adoption in the tourism industry, to the best of our knowledge no systematic study has yet been devoted to understanding the dynamics behind this trend. Nonetheless, diffusion of innovation has been considered a very interesting phenomenon for decades. With the increasing rate of technological innovations and the revolution of digital technologies, capturing how certain advances diffuse has become of primary importance not only to understand the socio-economic trends but also to create opportunities for service innovations. This is particularly true for specific industries, like tourism, where digital technologies can impact the communication, the user experience or even the definition of completely new business models. Diffusion of innovation theories show that in a social system the influence of peers impacts the diffusion of a certain innovation (Rogers, 2003). While a large number of 
previous studies focus on the influence of perceived value of the new technology on the users' attitudes (Tzeng and Haung, 2011), the aim of the present research is to investigate the dynamics behind the level of diffusion of information and awareness about new technologies in tourism. Thus, we study the public debate on Twitter, a popular microblogging platform, to identify communication dynamics and patterns of information exchange emerging around new technological innovations (such as blockchain and bitcoin) in tourism. The analysis of social media in general, and Twitter in particular, has been considered effective to assess the public opinion on a wide array of topics (Bian et al., 2016; Ibrahim and Wang, 2019), both for analytical (O'Connor et al., 2010) and for predictive (Asur and Huberman, 2010) purposes. Moreover, since social media are fundamentally a many-to-many communication tool embedded in social networks, there is considerable research (Williams et al., 2015; Cheong and Cheong, 2011; Stieglitz and Dang-Xuan, 2013) adopting the social network analysis (SNA) approach to reveal and investigate the social network structures and the communication flows associated with online debates. Thus, analysing the public debate on Twitter through SNA we measure the diffusion of information about specific technological innovations as a factor impacting the diffusion of the innovation itself. In fact, numerous scholars have underlined how the dynamics of information-exchange influencing innovation diffusion still remain an unexplored area of research (Grover et al., 2019; Min et al., 2018). Thus, our main assumption is that users who are at least informed about the existence of specific technological features and capabilities represent the basis for technology diffusion. In this sense, the degree of knowledge related to technologies is a sort of antecedent of innovation diffusion and adoption. In sum, the paper attempts to answer the following research questions: "How does the information exchange on social media influence the attitude and the shared perception towards new technologies in tourism?", and subsequently, "How is the online debate influenced by individuals' roles and network structure emerging in the online social system?"

\section{Literature review}

Innovation can be seen as an idea, practice or object that is perceived as new by an individual or other unit of adoption (Rogers, 2003). The newness of an innovation is thus a subjective concept that strongly depends on the perception of the individuals in the social systems in which the innovation disseminates. Diffusion of innovation can be defined as "the process by which an innovation is communicated through certain channels over time among the members of a social system" (Rogers, 2003). The four main elements of this concept are (1) innovation, (2) communication channels, (3) time and (4) social system. Moreover, with respect to complex technologies, the social network view of innovation diffusion stresses the importance of networks, and of network dynamics, in influencing innovation diffusion (Troshani and Doolin, 2007; Katona et al., 2011). Thus, the implementation and dissemination of technological innovation are dependent on the perception of newness of the innovation in question, its value and the information received from the social environment (Bass, 1969; Rogers, 2003; Karahanna et al., 1999; Venkatesh et al., 2003). Indeed, information exchange in a digital context, like social media, ignites a mechanism of electronic word-of-mouth that raises awareness about a new technology. Starting from these common considerations, the literature review, proposed in the following paragraphs, aims to put in evidence: (1) what are the main drivers (in terms of perceived benefits) that could influence the perceptions of users about the adoption of a new technology, product or solution; (2) the role of networks, in which users interact, in supporting this diffusion process by allowing information exchange; (3) the role of specific players - named knowledge brokers - in influencing this information exchange.

\subsection{Technology diffusion in tourism: perception in tourism}

Previous authors widely discussed the role of perceived value of new solutions in different contexts (Cravens et al., 1988; Monroe, 1990; Porter, 1990; Sheth et al., 1991; McDougall and
Innovation diffusion in tourism 
Levesque, 2000; Sweeney and Soutar, 2001; Omar et al., 2007). In particular, Sheth et al. (1991) classified the perceived value into functional value, epistemic value, conditional value, social value and emotional value. More specifically, the functional value is considered the primary driver of choice, based on specific products' attributes, while the epistemic value is associated with curiosity, novelty and satisfaction. Moreover, the epistemic value has a "stronger influence on intention if mediated by attitude" (Sheth et al., 1991, p. 162). In addition, the conditional value derives from the consideration of determined contingencies and the social value is associated with social stereotypes. Finally, the emotional value reflects specific feelings. Overall, the way in which users determine how valuable a product is also forms their perceptions about the product (or service).

In general, existing studies explore the links between users' perceptions and their decision to use new solutions. In particular, if we refer to the tourism industry representing the context of this study, we can investigate the potential benefits associated with the usage of new technologies (e.g. blockchain). In fact, these solutions enable businesses, customers and stakeholders to create value, to take advantage of innovation and to redefine the roles of touristic operators (Marchegiani and Rossi, 2016). According to Buhalis (1998), efficiency improvement, maximization of profitability, services' development and long-term prosperity of tourism enterprises are the main benefits deriving from the use of technology. Existing literature also focuses on the development of new service products with minimal costs (Min, 2008), on the overall improvement of tourists' travel experience, on provision of more intelligent platforms, on information sharing within destinations and on better tourism resources allocation (Staab et al., 2002; Neuhofer et al., 2013). Moreover, Cabiddu et al. (2013) find that higher performance in terms of value appropriation comes from the strategic fit between each initiative and firm's objectives, synergy among the partners and IT readiness. In addition, according to Stamboulis and Skayannis (2003), the implementation of technology is able to attract feedback from customers, raise the sense of involvement and belonging, increase customers' loyalty and encourage more interactive learning. Furthermore, the implementation of IT technologies empowers cost reduction, data and processes integration like administration, production, communication and cooperation between tourism production and distribution ..partners (Buhalis and O'Connor, 2005; Karinsalo and Halunen, 2018; Treiblmaier and Önder, 2019). Additionally, technology offers services specialization, flexible network configurations, a combination between consumer and internal business processes and stakeholders' integration (Werthner, 2003).

Typically, interoperability, personalization and constant networking are relevant aspects connected to the use of new technologies (Buhalis and Law, 2008); moreover, intelligent systems provide support for tourist information searching and decision-making processes (Gretzel, 2011). The emergence of connected devices, the increasing adoption of blockchain technologies, the management of huge amounts of data, the involvement of millennials in travel planning and the use of travel packages nurture the development of economies of scale (Xiang et al., 2015) and create better opportunities for action in the social media space (Wang et al., 2014). At the same time, the integration between online and offline channels, the customer-centric approach, the optimization of revenue generation due to the use of predictive analytics and the formation of new business models encourage the co-creation with multiple stakeholders (Colombo and Baggio, 2017; Neuhofer et al., 2013; Meriläinen, 2017; Karinsalo and Halunen, 2018; Stankov and Filimonau, 2018; Buhalis and Sinarta, 2019). Research also focused on the trust related to the availability and immutability of information as well as on the creation of a cooperative environment and common open scheme for applications, data, transactions and identification of the players (Colombo and Baggio, 2017; Treiblmaier and Önder, 2019). Furthermore, the adoption of smart devices increases the level of knowledge and socialization of people, valorizing specific destinations' geographical attributes and building networks between territory's resources and tourist activities. 
Similarly, the gamified mobile experiences are gaining importance in promoting tourism destinations (Garcia et al., 2019; Swacha, 2019).

Among other solutions, the influence of blockchain technology is growing (Nam et al., 2019). Although the smart tourism platform is not fully integrated (Khan et al., 2017), the usage of blockchain encourages the management of different transactions related to areas such as sales, operations and administration. In this sense, this new technology creates several connections between internal and external stakeholders (Boucher et al., 2017; Nam et al., 2019). The diffusion of blockchain is associated with the use of smart contracts and digital currencies that ensures a high level of anonymity due to the use of wallets not directly connected to the identity of the owners (Polasik et al., 2014; Leung and Dickinger, 2017). According to Statista (2020), the number of blockchain wallet users increased globally from around 11 million in 2016 to over 44 million in 2019. The usage of blockchain allows users to save time and to locate travel data in one token, facilitating the management of tickets, rationalizing operations and saving transaction costs (Goldman Sachs, 2014; Karinsalo and Halunen, 2018). Furthermore, the use of blockchain is associated with higher trust in rating systems and more reliability in users' reviews; moreover, online travel agencies adopt this technology aiming to improve services and disintermediate activities (Nam et al., 2019). According to Cong and He (2019), "blockchain and smart contracts can sustain market equilibria with a larger range of economic outcomes" (p. 1787). The role of blockchain is also related to the improvement of supply chain networks with the creation of smart contracts, and collaborative and secure networks (Saberi et al., 2019).

To conclude, digitalization can be considered a source of competitive advantage for companies operating in travel and tourism because it reduces administrative and personnel costs for flight booking processes (Jeon et al., 2018), it increases customer satisfaction (Stankov and Filimonau, 2018; Zhang et al., 2019; Presenza et al., 2019; Buhalis and Sinarta, 2019) and it produces clearer and more dynamic communication of information (e.g. word of mouth) within a definite network of interactions (Arenas et al., 2019; Zhang et al., 2019). Finally, the data sharing and the higher accessibility (Femenia-Serra et al., 2019; RuedaEsteban, 2018) create smart and agile ecosystems in which several stakeholders are involved (Kwok and Koh, 2018; Buhalis and Sinarta, 2019) and able to find a "synergetic way to support customers in pre-, during-, and post-sales activities" (Capriello and Riboldazzi, 2019, p. 3). According to Capriello and Riboldazzi (2019), the achievement of these benefits derives from the development of intelligent and smart systems which allows users to create a more personalized tourism experience and a "more convenient, safe, exciting and sustainable living spaces for both residents and tourists" (Gretzel et al., 2015, p. 185).

\subsection{Technology diffusion in tourism: a network-based approach}

The explosion of connectivity, generated by the rapid growth of the internet, has facilitated the open exchange of information between several players (Evans and Wurster, 1999). At the same time, the development of digital networks has encouraged the sharing of ideas and distribution of knowledge (Sproull and Kiesler, 1991). The knowledge exchange in a digital context occurs through the creation and communication of information between contributors who have different roles and purposes. In particular, information diffusion dynamics are useful to explain why certain innovative solutions (e.g. blockchain) are adopted more rapidly than others. For instance, Rogers (2003) investigates the role of influencers and opinion leaders in influencing others, considering their central position within a network. Moreover, several studies associate the role of specific players' characteristics with their influence on the electronic word-of-mouth (eWOM) and, in turn, on information diffusion (Araujo et al., 2017). Among other authors, Rogers (2003) explores the strategic position of individuals and intermediaries within communication networks with the aim of analysing the level of
Innovation diffusion in tourism 
innovation diffusion. The theories that deal with the dynamics of innovation diffusion focus on the decision to adopt or reject an innovation on the basis of personal beliefs that potential users form about the innovation. Theories on the diffusion of innovation (DoI) are therefore useful to understand the dynamics of innovation diffusion and to predict the likelihood and rate of its adoption (Chen et al., 2002).

Generally, the diffusion of innovations over time can be represented by a S-shaped curve: at the beginning only a few agents adopt a specific innovation, then a sharp increase in the number of adopting actors takes place after which a deceleration in the adoption rate follows and the curve grows at a decreasing rate (Bass, 1969). Economists explain the S-curve pattern in terms of a balance between supply and demand: the upsurge in the diffusion is caused by the decrease of innovation costs, which would increase demand and, therefore, diffusion. The basic idea of the model is that one new solution (or product) will be implemented at a time $t$, given no purchase has yet been made, is a linear function of the proportion of the population that has already adopted the solution (or the product). In explaining the adoption over time, we have to take into consideration two coefficients: $p$ and $q$. The first, $p$, is called "the coefficient of innovation", or external influence, and it refers to the probability of initial purchase independent of the influence of previous buyers, under the effects of mass media coverage or other external factors. On the other hand, $q$ is called "the coefficient of imitation", or internal influence, and it refers to the pressure on imitators from previous buyers, through, for example, the mechanism of WOM. From Rogers' perspective, the diffusion of innovations is to be regarded as a two-step process. Firstly, the smartest and most innovative segments adopt it. Afterwards, they put pressure on the other segments, thus making them adopt the innovation in turn. This implies that the early adopters allow the take-off, boosting the diffusion process and the crossing of the chasm. In addition, Lyytinen and Damsgaard (2001) stress the relevance of a network approach while studying complex and interactive innovations. In case of simple and relatively stable innovations, researchers have traditionally focused their attention on two units of analysis: individual adopters and adopter populations. These units of analysis are fixed for the whole study and over time. In the case of complex and interactive innovations, this choice of analysis units alone is not sufficient, though it can help obtain interesting insights of how individual adopters react or behave in relation to available complex technologies (Lyytinen and Damsgaard, 2001). Specifically, a network-based approach is needed when the adoption of innovation involves two or more independent adopters and often requires the involvement and/or the availability of several other actors in the adoption process. This need relies both on the structure of the competitive environment that involves different kinds of parties (consumers, companies, institutions, service providers and so on) and on a set of mechanisms that are activated by the spread of interactive innovations. Arthur (1989) highlights this point by introducing the concept of attractiveness of an innovation. Indeed, the more attractive a technology becomes to users when it is diffused and others adopt it, the trendier it becomes (Arthur, 1989).

\subsection{Technology diffusion in tourism: social cognitive theory and the role of knowledge brokers}

Among the most known DoI theories, the social cognitive theory (SCT) provides an interesting theoretical framework for the investigation of behavioural and environmental factors which influence the dispositions of each individual (Bandura, 1986; Wood and Bandura, 1989). In this sense, the interaction between specific factors (behavioural and environmental ones) also affects the users' intentions. According to the SCT, the role of the psychological behaviour of individuals and groups becomes crucial in explaining the reasons to adopt certain conducts rather than others (Bandura, 1986), as well as the nature of different individual behaviours (Chan and Lu, 2004; Ratten and Ratten, 2007). Specifically, single 
behaviours are evaluated through the individuals' expectations which can be also mediated by the observations of others (LaRose and Eastin, 2004; Van Dijk, 2012). Thus, the major premise of SCT is that individuals can influence the actions of other users in the same social system (McCormick and Martinko, 2004; Carillo, 2012).

A broad amount of research has been conducted in relation to the different roles and characteristics of the individuals participating in the networks (Millar and Choi, 2003; Burt, 2004; Winch and Courtney, 2007). In these various studies, the role of knowledge brokers becomes increasingly important to explain the success of technology diffusion and adoption (Czarnitski and Spielkamp, 2003; Hargadon, 2003). Knowledge brokers are defined by Hargadon and Sutton (1997) as intermediaries who promote the transferring of new ideas between different parties. In particular, they increase the base of available information within a specific context characterized by innovation, thus enhancing the possibility to achieve a competitive advantage (Hargadon and Sutton, 1997). Moreover, according to Hargadon (2003), they are able to integrate the quality of ties with the speed of knowledge transfer among the members of a network. In this sense, the role of knowledge brokers appears to be crucial in helping the innovation through the combination of existing technologies in new ways (Hargadon, 1998; Howells, 2006).

\section{Research methodology}

The focus of this article is to study how information about specific innovations is exchanged and how attitudes towards them are shared and mutually shaped on social media as enabling factors for innovation diffusion, particularly at the knowledge stage (Rogers, 2003).

Thus, we focus on the popular microblogging platform Twitter to identify user communication and analyse social network structures of the social media debate on specific technological innovations (namely, bitcoin and blockchain) in the tourism sector. Twitter is a popular social network, with 150 million monetizable daily active usage in the fourth quarter of 2019, [2] and has already been studied as an effective tool for both analysing (O'Connor et al., 2010) and predicting (Asur and Huberman, 2010) public opinion on a wide range of topics. Twitter, as well as social media in general, is fundamentally a many-to-many communication environment, based on social network structures and is a valuable platform for monitoring public debate (Lischke and Fabian, 2016). Twitter is therefore a research domain suitable for studying the structures of social networks and the behaviour of knowledge brokers that shape the dynamics of information before and during the diffusion of a technology.

In line with the research focus, we adopted SNA as an approach specifically designed for the study of information exchange (Haythornthwaite, 1996) and the patterns of relationships between social actors (Wasserman and Faust, 1994; Aggarwal, 2011). SNA has already been applied in several research studies focused on Twitter, ranging from the study of emergency crises (e.g. Cheong and Cheong, 2011) to international politics (e.g. Jörgens et al. 2016). In addition, SNA is considered a primary technique for identifying key contributors in the information exchange process and for detecting sub-communities that share a common perspective on selected topics (Fan and Gordon, 2014). SNA has also been used as a predictive modelling approach, for example targeting certain actors or sub-network because they are assumed to have a stronger propensity to buy a particular product (Bonchi et al. 2011). Thus, we apply SNA to the study of the public debate on Twitter about blockchain, an emerging technology that is attracting significant attention with applications in multiple industries ensuring transparency, traceability and security of processes and transactions (Nofer et al., 2017; Saberi et al., 2019; Nam et al., 2019).

We also adopted sentiment analysis to derive users' sentiments regarding the implementation of blockchain in tourism. Sentiment analysis is adopted to detect opinions
Innovation diffusion in tourism

$\longrightarrow$


and sentiments from unstructured documents, identifying whether a certain text (or some of its parts) signals a positive (favourable) or negative (unfavourable) opinion towards the subject (Nasukawa and Yi, 2003; Pang and Lee, 2008; Bae and Lee, 2012). Sentiment analysis usually is used to infer polarity (e.g. only favourable or unfavourable opinions) rather than trying to extrapolate different degrees of a continuous sentiment. We adopted a lexicon-based technique, a term-based matching system based on a list of words pre-coded for polarity (Taboada et al., 2011) and largely used in previous studies. This approach has been proved effective also to identify the sentiment analysis on Twitter, performing the analysis of short texts (as tweets) even without training and testing (Thelwall et al., 2011; Bollen et al., 2011). The assumption is that the network of tweets collected through a selected combination of keywords (e.g. \#blockchain and \#tourism) is a proxy of the interest towards the use of distributed solutions, such as blockchain and bitcoin, in the tourism industry. From a conceptual point of view, the study builds on the consideration that technology and social aspects are not dichotomous, but rather inseparable (Bolici and Giustiniano, 2013). Adopting this approach, the paper (1) identifies the characteristics and the dimensions of the public debate on distributed systems in the tourism sector; (2) investigates the structure of the information networks and the relative positions of the individual nodes (accounts) to investigate the capabilities and limitations of the communication dynamics; (3) conducts a sentiment analysis to understand the positive or negative attitude of the actors towards the object of their discussion.

\subsection{Data collection}

We structured the data collection in three different phases: the first to identify the relevant keywords to be analysed; the second to collect the data and to study the whole communication network; the third to focus the analysis on four specific sub-networks represented by the most frequent hashtags combinations.

In phase 1, we identified a set of keywords (\#hashtags) that would represent the Twitter debate on technological innovation in the tourism sector. As shown in ab. 1, we classified a set of frequently used domain keywords (\#tourism, \#travel, \#hotel \#holidays, \#bandb, \#booking, and \#vacation) and a set of hashtags representing technological innovation (\#blockchain and \#bitcoin [3]).

In phase 2, a script was set up to automatically collect all the tweets (including retweets and answers) mentioning all the possible combinations of domain and technological hashtags, resulting in 14 keywords dyads. For example, as shown in Table 1, the dyad "\#Blockchain and \#Travel" was mentioned in 11,901 tweets. The script collected data between 13 March and 13 December 2019, for a total of 29,051 tweets and retweets, with the large majority $(25,960)$ generated from the first six dyads of those hashtags ((1). \#travel and \#blockchain; (2). \#travel and \#bitcoin; (3). \#tourism and \#blockchain; (4). \#tourism and

Table 1.

Tweets frequency for all the combinations of all the domain/ technology hashtags

\begin{tabular}{lrrr}
\hline Hashtag & \#Blockchain & \#Bitcoin & Total \\
\hline \#Travel & 11,901 & 7,538 & 19,439 \\
\#Tourism & 3,777 & 1,149 & 4,926 \\
\#Hotel & 1,243 & 352 & 1,595 \\
\#Vacation & 801 & 556 & 1,357 \\
\#Holidays & 613 & 202 & 815 \\
\#Booking & 416 & 360 & 776 \\
\#B\&B & 94 & 49 & 143 \\
Total & 18.845 & 10.206 & 29.051 \\
\hline
\end{tabular}


\#bitcoin; (5). \#hotel and \#blockchain; (6). \#hotel and \#bitcoin), shared by over four thousand accounts. We run the SNA on the above identified communication network in order to study its overall characteristics and dynamics. A node in the network represents a twitter profile participating in the public debate (tweeting, retweeting or answering a tweet with the selected dyad of hashtags), while the links among two nodes represent the information exchange directly linking two profiles (e.g. a profile answers or retweets a tweet generated by another contributor).

In phase 3, we focused the analysis at sub-network level, studying individually each one of the four most participated sub-networks: (1). \#travel and \#blockchain; (2). \#travel and \#bitcoin; (3). \#tourism and \#blockchain; (4). \#tourism and \#bitcoin. We have chosen not to discuss in details the last two dyads (\#hotel and \#blockchain; \#hotel and \#bitcoin) because their analysis did not provide additional information over communication dynamics and characteristics of the general network.

\section{Social network analysis}

Data analysis is conducted at two different levels: (1) the whole dataset is analysed to have a general overview of how the information about blockchain is flowing and spreading; (2) the sub-set of four specific networks - originated from four different keyword dyads (e.g. the network emerging using the keywords \#tourism and \#blockchain) - is analysed in depth to investigate its specificities.

The first step is to perform a descriptive analysis of frequencies (both on profiles and tweets) to identify how the different networks (combination of keywords) perform on social media. Next, the two most dynamic networks were selected (\#tourism, \#travel with the two technological keywords), conducting a SNA on the sub-datasets in order to identify similarities and differences in their characteristics.

Finally, a sentiment analysis was performed on the text of tweets to gather information about users' sentiments regarding the implementation of blockchain in tourism.

\subsection{Analysis of the overall network}

4.1.1 Descriptive longitudinal analysis. The analysis of daily frequencies of nine months of data (Figure 1) shows that there is a diffused and constant interest on the general topic with an average of around 105 tweets per day. However, we identified several spikes in public debate, three of the top four $(01 / 06 / 2019 ; 31 / 07 / 2091 ; 24 / 08 / 2019 ; 25 / 09 / 2019)$ were linked to events dealing with the implementation of Blockchain Technology (Table 2), the largest one being recorded on the 24 August, with 774 published tweets.

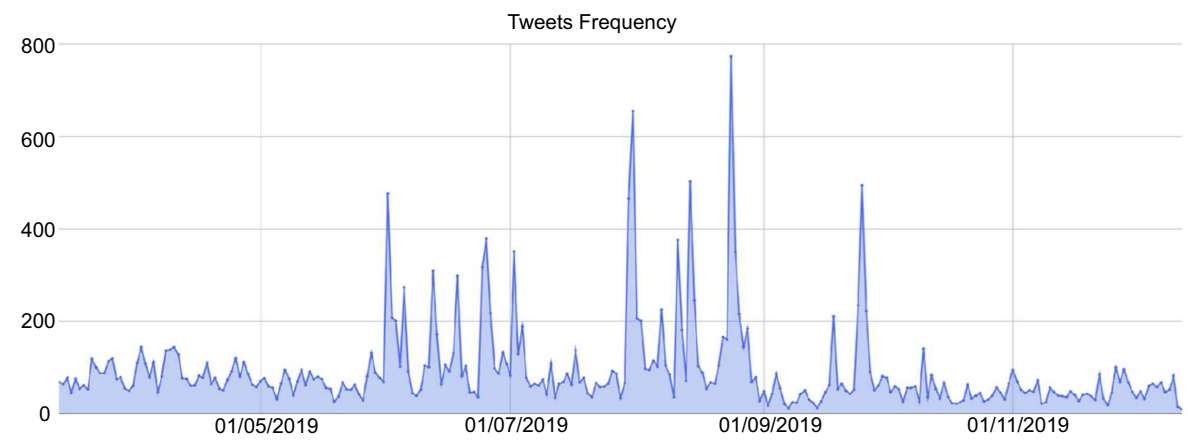

Innovation diffusion in tourism

\section{,}




\section{TQM}

\begin{tabular}{lcl}
\hline Date & \#Tweets & Events \\
\hline 01/06/2019 & 476 & Lightning Hackday \\
31/07/2019 & 656 & $\begin{array}{l}\text { Munich } \\
\text { Hyperledger } \\
\text { Member Summit }\end{array}$
\end{tabular}

Description

One full day of speakers dealing with possible application of Blockchain to Lightning

Hyperledger Member Summit is the annual event of the open source collaborative effort created to advance crossindustry blockchain technologies. It is a global collaboration, hosted by The Linux Foundation, including leaders in finance, banking, Internet of Things, supply chains, manufacturing, and technology

24/08/2019 $774 \quad$ No event

No major event linked to potential applications of

25/09/2019 $494 \quad$ Blockchain Live

Blockchain/Bitcoin was scheduled

Blockchain Live is a groundbreaking festival of content and

Table 2.

London collaboration that connects the fragmented ecosystem to drive meaningful discussion and debate on how best to accelerate global adoption of blockchain

Analysis of spikes in tweets frequency

4.1.2 Social network analysis on the complete network. The complete network of communication regarding tourism associated with blockchain and bitcoin on Twitter is represented in Figure 2.

The network includes a total of 4,707 twitter profiles (nodes) and 7,594 single retweets (edges). A total of 103 communities of users were identified, usually centred around specific profiles of alternative service providers or new "travel cryptocurrencies" services. Regarding the network, its density is extremely limited (almost 0 , as could be expected given the large number of nodes) and is highly centralized around 11 different nodes (profiles) whose contents are often retweeted. Notwithstanding an extremely low number of average followers (less than 3,000 followers), the 11 mentioned nodes have a high engagement rate, showing that the resonance of the topic is potentially high.

From the data we gathered and analysed, we could immediately observe a highly centralized network, where we could note the presence of agents that are referred to scientific literature as "brokers", defined as actors which connect two otherwise unconnected users or fills gaps or network holes in the social structure (Burt, 1992; Gould and Fernandez, 1989) and for this reason they are the only players which allow other parties to access and share valuable information already existing within the network (Stovel and Shaw, 2012).

At the same time, we can identify a very high turnover among the nodes that take part in the public debate. As shown in Table 3, a very few nodes (37) were part of the public debate for the whole 9 months (the number of permanent participants is calculated as the number of nodes actively participating in all the previous periods). At the same time, there is an increasing number of nodes that periodically join the discussion just in one specific moment (the percentage of one-time participants grows from around $20 \%-70 \%, 77 \%$ and $75 \%$ in the last three periods). The result is a high turnover in the number of users joining and leaving the public discussion.

From a content perspective, most of the tweets were focused on the possibility to acquire services (air travels/hotels) through blockchain/bitcoin technology.

The structure of this network clearly underlines its high centralization: almost all communities are all gathered around a single node, all communications are centred around the focal point of the specific community and there is often a low level of communication intraand inter-communities.

In Table 4 we identified five of the most important brokers in the network.

We also performed a sentiment analysis (a specific type of content analysis) to investigate if the discussion about innovative technology in tourism had a positive, neutral or negative 
Innovation diffusion in tourism

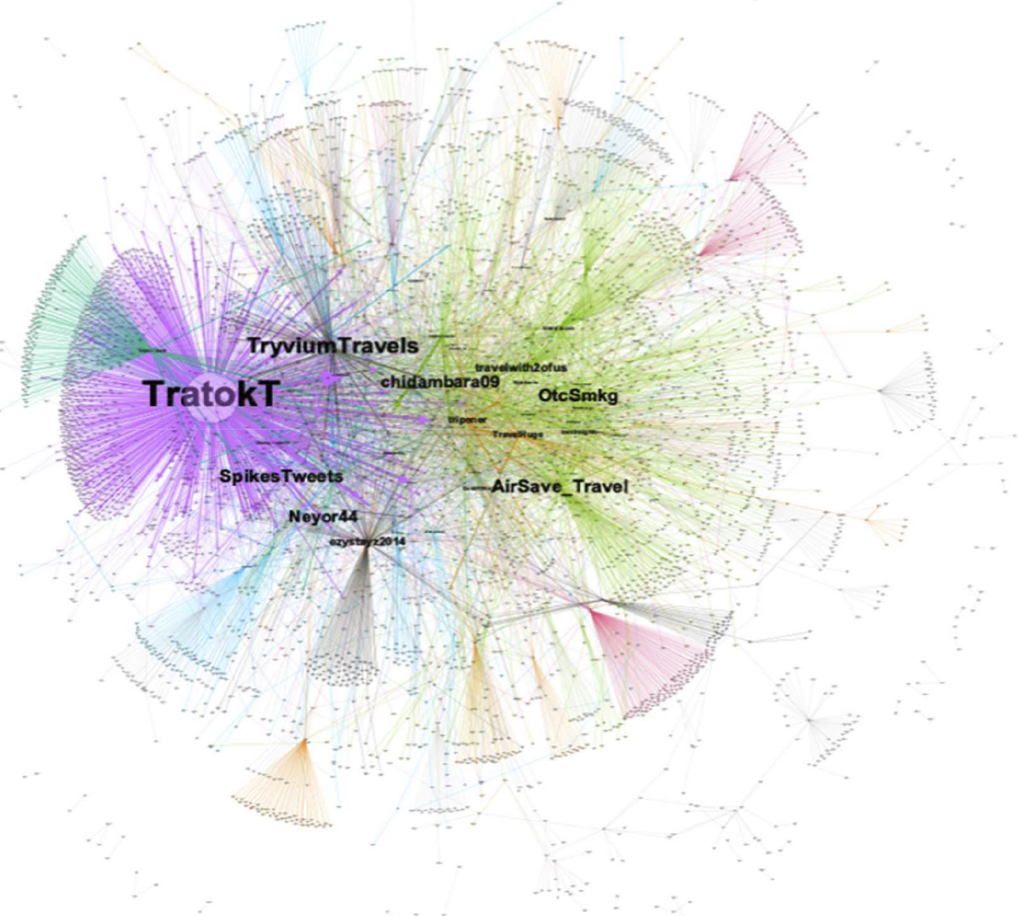

Figure 2.

All Tweets, all keywords Network

framing. The result of our analysis showed that around $46 \%$ of the tweets and retweets were adopting a positive frame in the discussion, around $45 \%$ neutral and only around $8 \%$ a negative one (with around $1 \%$ of the tweets failing to clearly fit into the classification). Then, we discovered that the activity of the main broker (the profile "TratokT") had a strong impact on the sentiment of the debate: as shown in Figure 3, the content generated by Tratokt significantly increases the percentage of tweets with positive sentiment $(+5.7 \%)$ and has an even stronger impact in reducing the negative sentiment in the whole network $(-7 \%)$, while slightly increasing the neutral sentiment $(+1.3 \%)$.

\subsection{Analysis of four sub-networks (keywords dyads)}

The large network can be decomposed in four different sub-networks, each corresponding to one of the following keyword dyads (the largest networks per number of tweets among the 14 identified dyads): 1) \#travel and \#blockchain; 2) \#travel and \#bitcoin; 3) \#tourism and \#blockchain; 4) \#tourism and \#bitcoin. The four sub-network features are summarized in Table 5.

4.2.1 Sub-network 1: \#blockchain + \#tourism. The shape of this sub-network clearly resembles the global network (the one including all tweets), where a few nodes can be identified as knowledge brokers, given the large number of retweets per each post retweeted (Figure 4). Three key brokers were identified inside this network, each one of them 


\section{TQM}

Table 3.

Number of nodes with a continuous participation in the social debate

\section{PROFILES' LONGEVITY IN THE DEBATE}

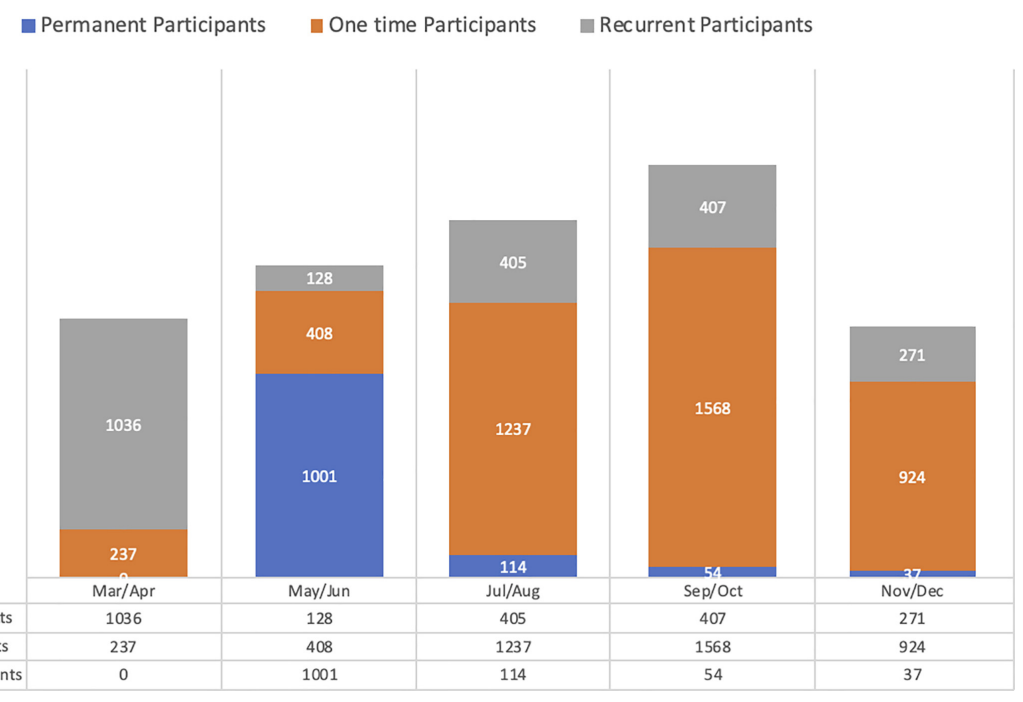

Top 5 brokers during the whole period (15/03-15/12)

\begin{tabular}{lrcc}
\hline Broker & Tweets & Avg. number of retweets (for each tweets) & Single unique tweets \\
\hline TratokT & 89 & 171.7 & 36 \\
Travalacom & 1,047 & 38.4 & 458 \\
Gaiminlo & 189 & 118.0 & 180 \\
Sanemavcil & 324 & 59.5 & 75 \\
Travelwith2ofus & 1874 & 5.5 & 362 \\
\hline
\end{tabular}

representing either a new cryptocurrency specific to travel or a platform allowing people to acquire services for travel (e.g. hotel rooms, flights) with cryptocurrencies.

Most of the tweets are focused on the possibility to buy touristic services (hotel, trips, travels packages) though crypto-currencies (not only bitcoin).

From a sentiment analysis perspective, the majority of the analysed tweets has a neutral $(55.4 \%)$ or positive $(42 \%)$ sentiment; less than $4 \%$ of tweets show negative sentiment (Figure 5).

4.2.2 Sub-network 2: \#bitcoin + \#tourism. This keywords combination represents the smallest sub-network among the ones analysed. Its structure is highly centralized: almost all of the edges are linked to a single node, the account of a travel cryptocurrency service (Figure 6).

From a sentiment analysis perspective, it's the network with the highest percentage of tweets with positive sentiment $(60.1 \%)$; less than $3 \%$ of tweets show negative sentiment, while the remaining $37.3 \%$ shows neutral sentiment (Figure 7).

4.2.3 Sub-network 3: \#blockchain + \#travel. This is the largest sub-network, with more than 200 communities and 200 information brokers. The high level of centralization of the network is clear, almost all nodes are centred around one single profile and there is almost no 


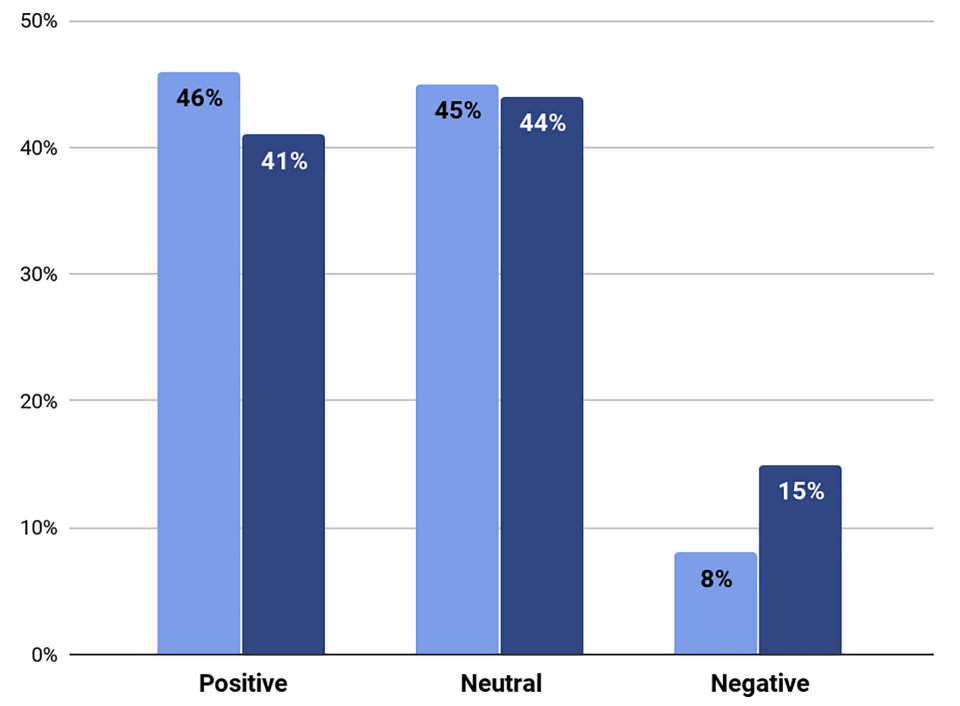

With TratokT

Without TratokT
Innovation diffusion in tourism

\begin{tabular}{|c|c|c|c|c|c|c|c|c|}
\hline $\begin{array}{l}\text { Technology } \\
\text { keywordogy }\end{array}$ & $\begin{array}{l}\text { Domain } \\
\text { keyword }\end{array}$ & \#Tweets & \#Nodes & \#Edges & Diameter & $\begin{array}{l}\text { Avg. } \\
\text { Degree }\end{array}$ & \#Clusters & Table 5. \\
\hline \multirow[t]{2}{*}{ \#Blockchain } & \#Tourism & 3,777 & 1,418 & 2,161 & 6 & 1,524 & 11 & $\begin{array}{l}\text { Analysis of the four } \\
\text { main sub-networks }\end{array}$ \\
\hline & \#Travel & 11,901 & 3,810 & 4,283 & 1 & 1,124 & 222 & combination of \\
\hline \multirow[t]{2}{*}{ \#Bitcoin } & \#Tourism & 1,149 & 542 & 569 & 4 & 1.05 & 9 & tourism/travel with \\
\hline & \#Travel & 7,538 & 2,304 & 2,337 & 1 & 1,014 & 198 & blockchain/bitcoin) \\
\hline
\end{tabular}

relationship between these isolated communities. Seventeen profiles were identified that have a central role within the network and with a higher degree of engagement; as per previous networks, those are the ones linked to cryptocurrencies or platforms that allow acquiring goods and services through cryptocurrencies (Figure 8).

From a sentiment analysis perspective, positive and neutral tweets are almost equal ( $44.5 \%$ and $45.6 \%$, respectively) with less than $10 \%$ of tweets having a negative sentiment (Figure 9).

4.2.4 Sub-network 4: \#bitcoin + \#travel. This combination represents a large and strongly centralized network in which almost all communities are composed of profiles and their tweets and retweets are centred around a few nodes. Seven profiles were identified as playing a central role within the network and with a higher degree of engagement; as per previous networks, those are the ones linked to cryptocurrencies or platforms that allow acquiring goods and services through cryptocurrencies (Figure 10).

It is clear that in each sub-network one profile has always played a central role: TratokT. Even with a relatively low number of followers $(4,429)$, this profile is capable of generating high levels of public interest and, on average, it has more than 100 retweets per post, taking on a significant role in the spreading of information about cryptocurrencies applied in tourism.

From a sentiment analysis perspective (Figure 11), this network shows the highest level of tweets with negative sentiment $(13.3 \%)$. 


\section{TQM}

Figure 4.

Blockchain + tourism network
Figure 5.

Sentiment analysis blockchain + tourism tweets

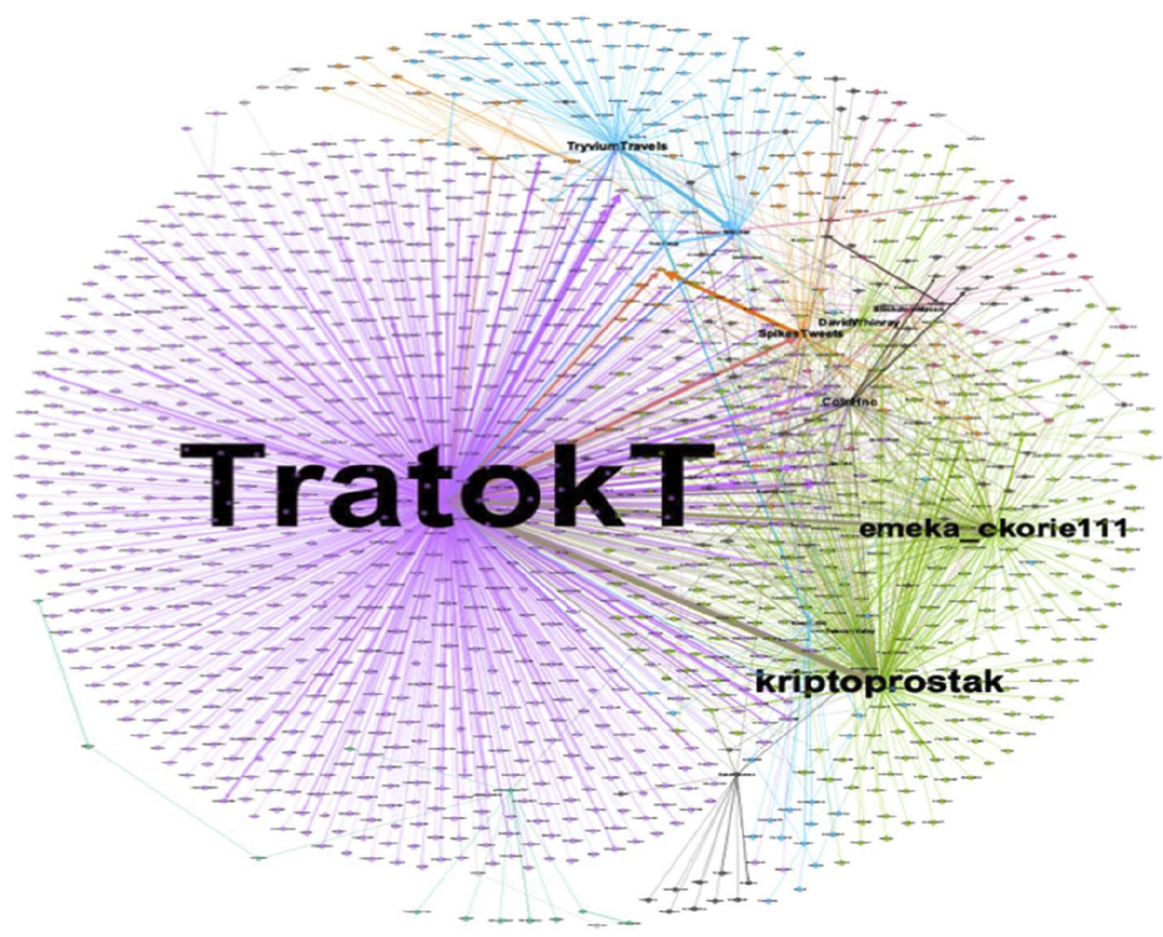

Blockchain \& Tourism Sentiment Analysis (Mar-Dec 2019)

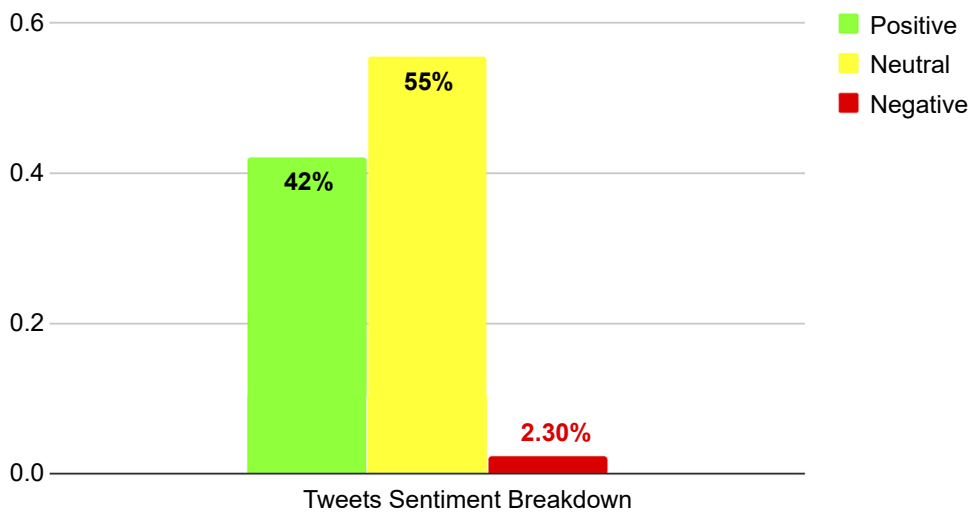

\section{Discussion of the results}

As confirmed by several studies, innovative technologies have been impacting the tourism sector for decades and they had a significant role in reshaping the business models, the organization and the marketing strategies of the players competing in the sector (e.g. Egger 


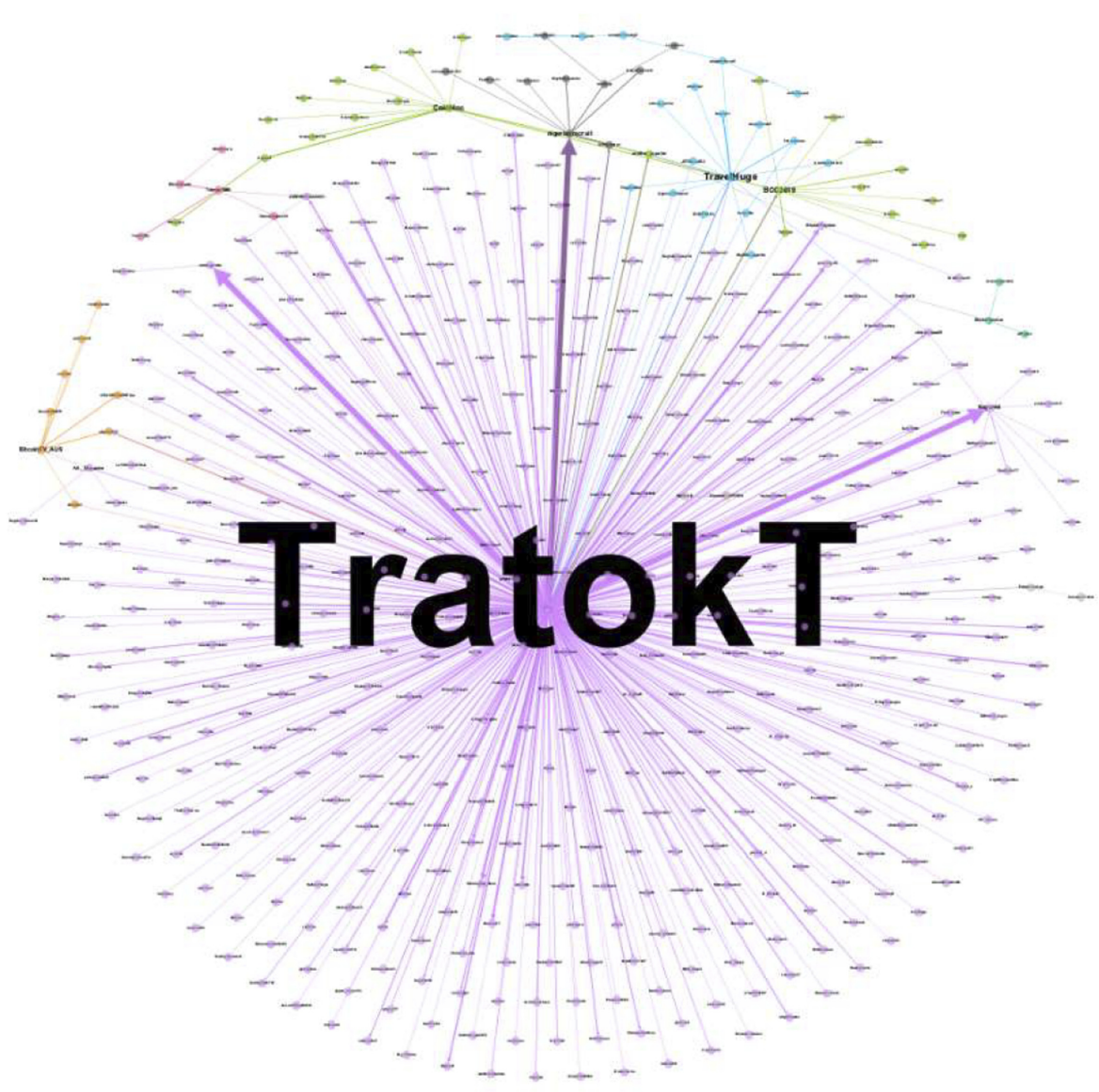

Innovation diffusion in tourism

Figure 6. Bitcoin + tourism network

and Buhalis, 2011; Middleton et al., 2009). Our study confirms that players in tourism are showing a growing interest towards blockchain. Indeed, through the analysis of the discourses posted on Twitter over a significant time span, this paper proposes an exploratory analysis of the information exchange and of the knowledge brokers which influence the diffusion of technology-based solutions in this specific industry. This growth in the level of interest by agents operating in the sector is further confirmed by the constantly increasing number of tweets and profiles discussing and debating this topic. Analysing the global network, including all profiles involved and all tweets published over a large time span (9 months), the analysis identified a set of specific characteristics shared by all single networks analysed in which all clusters are centred around one or more nodes, usually the profile of a user that offers innovative solutions for tourism. At a deeper level of analysis, the results of the SNA show that the \#travel network is currently the largest network $(73 \%$ of tweets dealing with blockchain belong to this network) and has expanded more rapidly than the \#tourism network. Both networks are highly centralized, and the main contributors associated with cryptocurrency and its trade. The discussion about \#bitcoin generated a more positive debate ( $47 \%$ when combined with \#travel and $60 \%$ with \#tourism) while the one on \#blockchain was more balanced between positive and neutral (with neutral at $55 \%$ in 


\section{TQM}

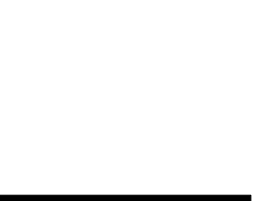

Figure 7.

Sentiment analysis bitcoin + tourism tweets

Figure 8.

Blockchain + travel network
Bitcoin \& Tourism Sentiment Analysis (Mar-Dec 2019)

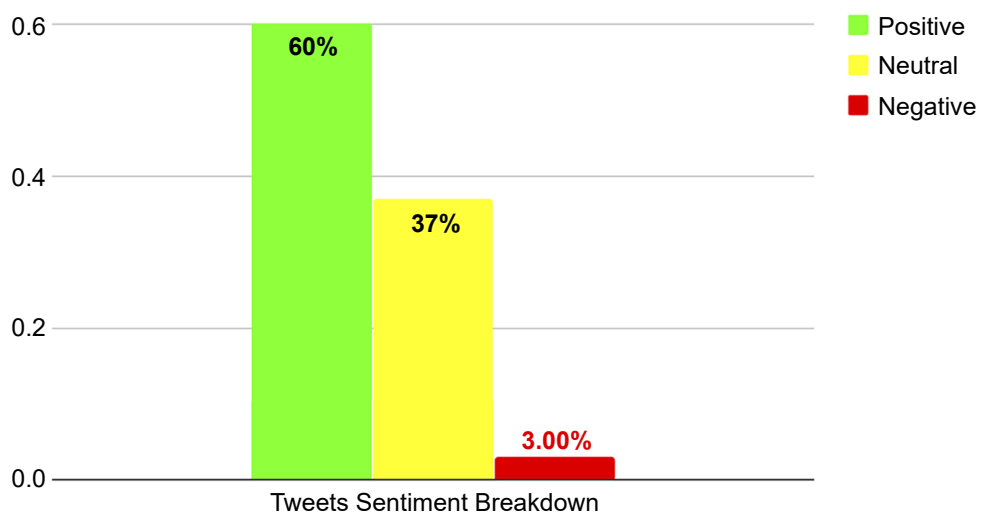

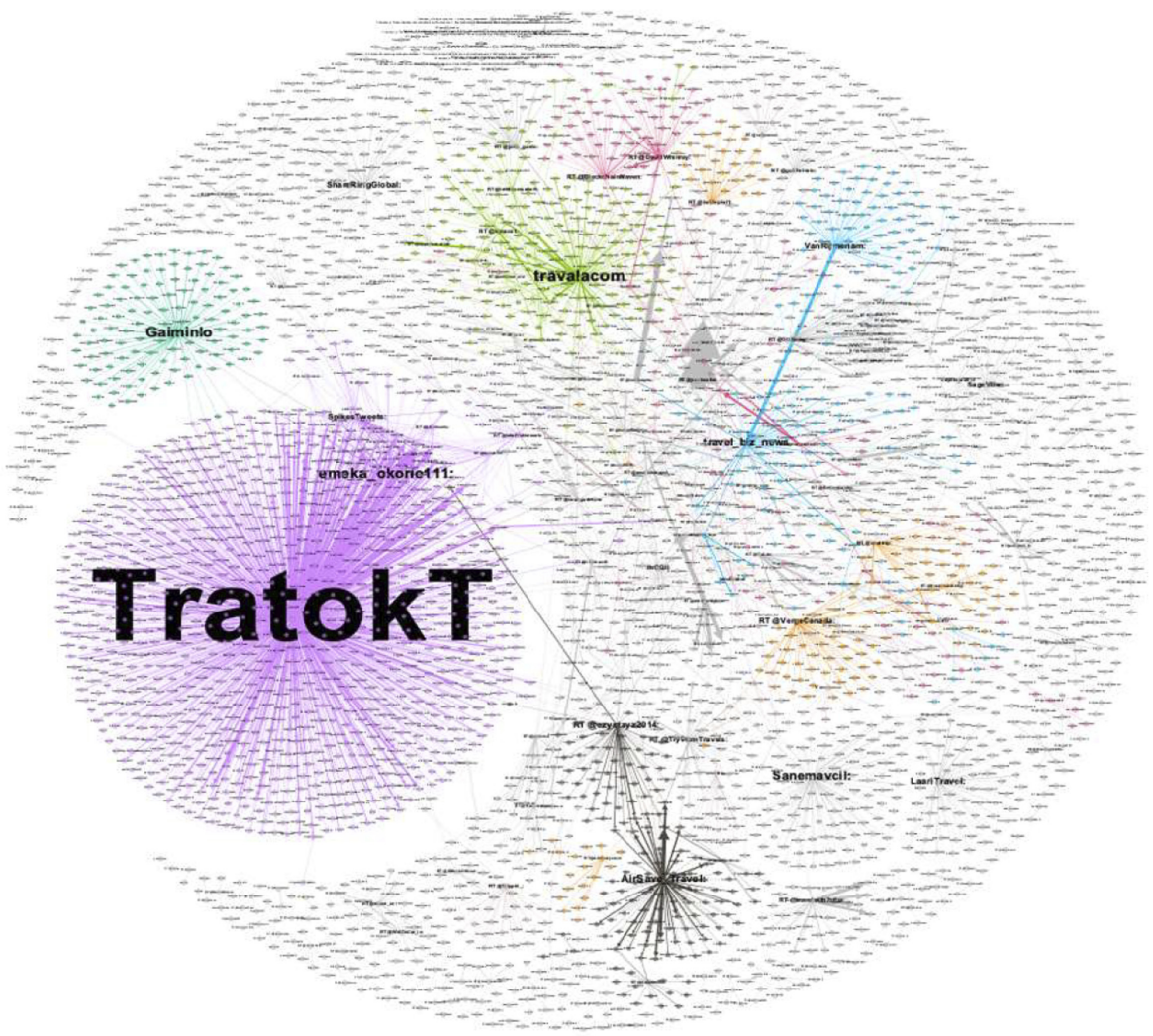


Blockchain \& Travel Sentiment Analysis (Mar-Dec 2019)

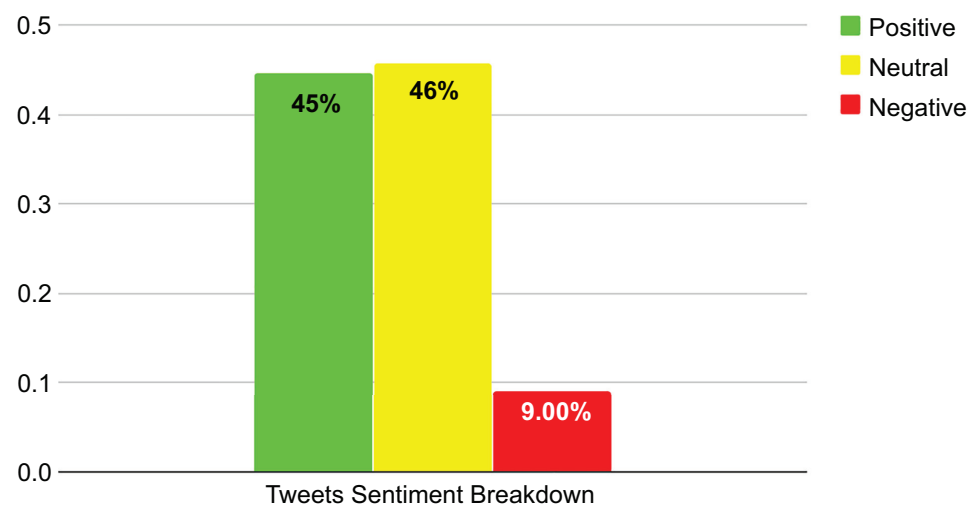

Innovation diffusion in tourism

Figure 9. Sentiment analysis blockchain + travel tweets

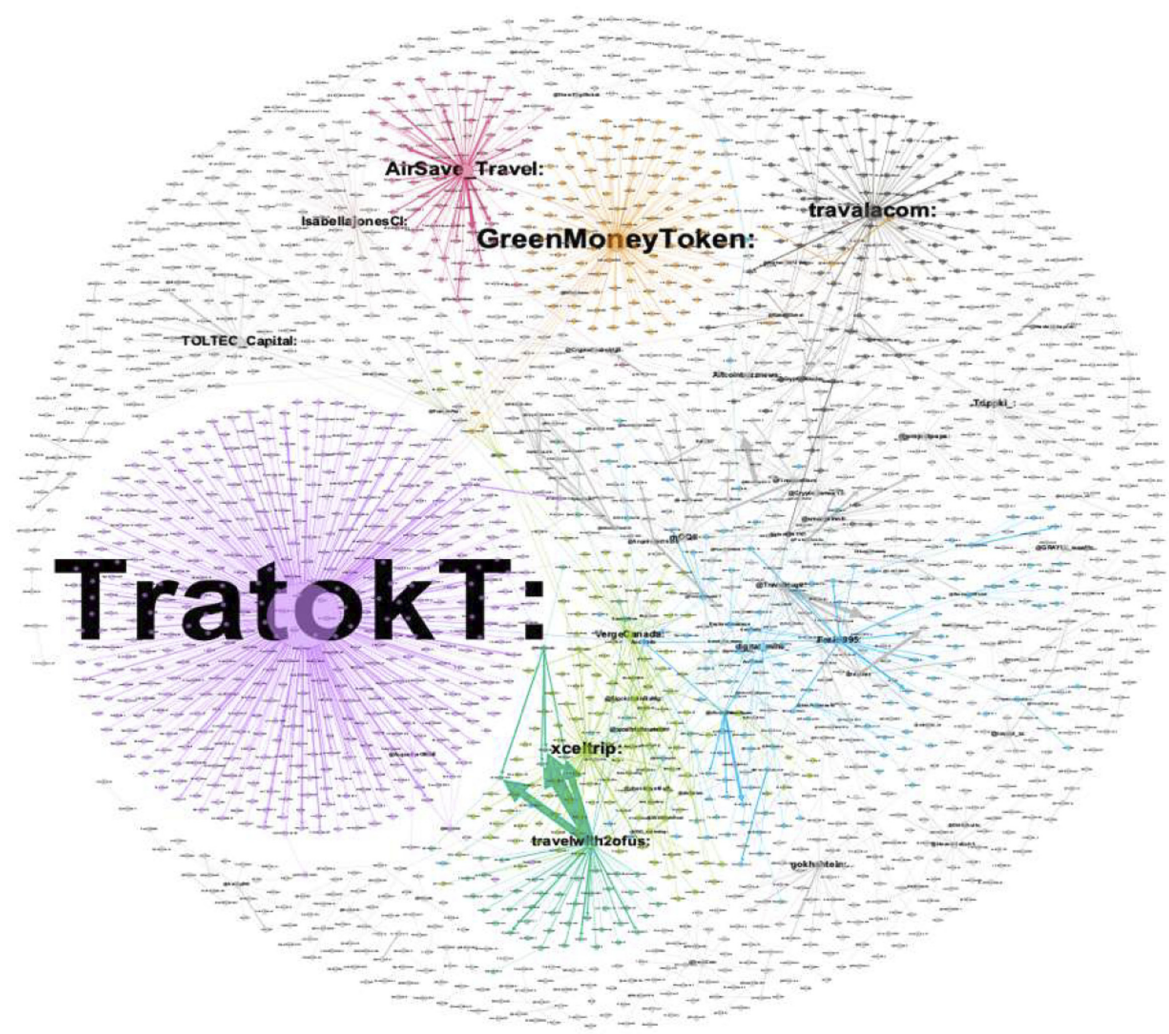

Figure 10. Bitcoin + travel network 


\section{TQM}

Bitcoin \& Travel Sentiment Analysis (Mar-Dec 2019)

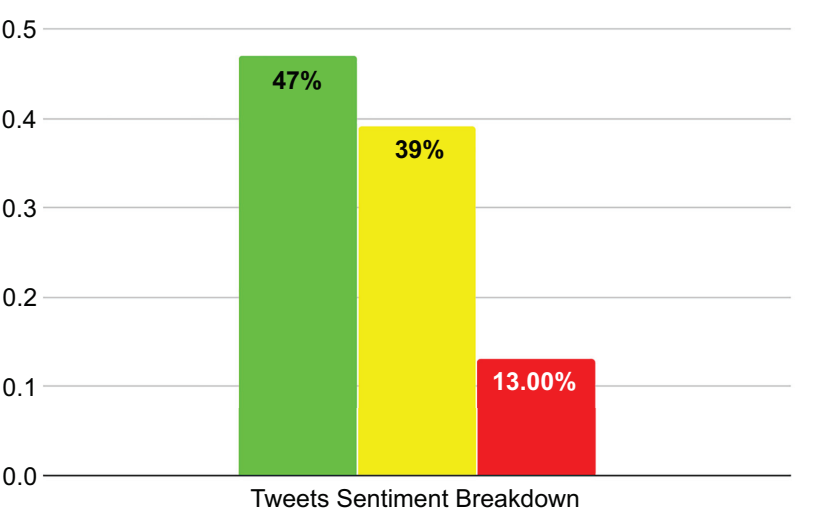

Figure 11.

Sentiment analysis bitcoin + travel tweets

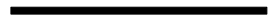

Positive

Neutral

Negative

combination with \#travel). This could reflect the difference in the nature of the debate, with the more specialized topics (\#blockchain) being discussed in a more technical way, while the solutions closer to the market (\#bitcoin) discussed by adopters and service providers with a more positive attitude towards the phenomenon. Combining the results coming from the SNA and the Sentiment Analysis, it is possible to underline that public interest on this specific topic is extremely high and positive as well. Discussion on social media is centred around potential applications and capabilities of such a medium that might allow people to buy products and services.

These results suggest that the analysis of the online discourse around a specific technological innovation is informative of both the level of interest and the popularity related to that innovation. Moreover, the analyses presented in this paper suggest methodological guidelines to analyse such online information sharing. In doing so, this paper contributes to the literature on information sharing about technological innovations, and potentially about innovation diffusion theories.

\section{Limitations and future research}

Notwithstanding the interesting results that were obtained through our study, this work has some limitations useful to trace future developments. Firstly, the statistical analysis has been conducted over a limited period of time (9 months). Even though social networks in general, and Twitter in particular, are digital platforms on which content is continually updated, a longer period of time will provide a deeper comprehension of the social interaction on the topics of the research. Secondly, a principal component analysis can be performed on selected tweets with the final aim of identifying the most discussed topics and technologies within the industry. As suggested by Jolliffe (1986), the identification of determined keywords connected to specific topics enables the selection of a smaller number of analysis' components, thus reducing the initial set of complex relations. For instance, in the present study, the adoption of tweets related to the provision of services like online bookings can provide interesting insights regarding innovation in touristic services obtained through new technologies (e.g. blockchain and bitcoin).

Future studies can investigate if the positive perception and the higher level of information exchange within the network can be associated with the increasing usage of specific technologies. Moreover, the content of the tweets can be analysed through content 
analysis (Kassarjian, 1977) with the aim of deepening the concepts discussed within the network of information. For instance, this analysis can reveal whether new technologies are adopted mostly for specific services or for others (e.g. online bookings).
Innovation diffusion in tourism

\section{Conclusions and implications}

In conclusion, the study examines the level of communication and information exchange between users on social media (Twitter) with the aim of exploring the diffusion of new technologies. Moreover, the sentiment analysis offers an interesting overview on positive or negative attitudes of the individuals towards the perception or the adoption of new technologies. This paper provides empirical findings at the network level (structural) and at the node level (individual account). At the network (structural) level, we discovered that the information network on blockchain in tourism consists of contributors who change very quickly over time (high turnover of accounts). Another interesting result is provided by the sentiment analysis, which shows that the debate evolves differently around technical and market issues. In fact, while the discourse around technical aspects of the innovation (i.e. tweets using \#blockchain) remains more neutral, the contributors engaging in market-related applications of the technology (i.e. tweets using \#bitcoin) seem more enthusiastic. At the node (individual) level, the article shows that some users (brokers like TratokT) are able to influence and encourage the public discourse in the social system (information centralization). At the same time, the brokers and the nature of the discussion around new technologies also have an impact on the definition of positive and negative sentiment towards a topic (sentiment influencer).

The implications of this study can be divided into two categories: theoretical and practical.

From a theoretical perspective, the results increase our knowledge about technology perception and technology diffusion. In particular, the network-based approach allows for the exploration of the information diffusion between two or more independent prospective adopters. Moreover, the visualization and analysis of social media data is helpful in investigating the level of discourse about new technologies within the information network. Supplementing evidence in line with the SCT, our study highlights how individuals have reciprocal influence in the same social system, in building and reinforcing a public debate around the new technology. This study also emphasizes the role of knowledge brokers in influencing the public debate that could encourage the innovation diffusion. In showing how the digital environments generate and stimulate knowledge brokering, this study contributes to the literature on networks and on brokerage within networks. From a practical perspective, the investigation of the information exchange about new technologies in tourism from a network perspective is essential to understanding the level of influence among users. The way in which users interact and share knowledge is especially beneficial for understanding their potential interest in the diffusion of new technologies. As suggested by Kane (2017), social media data can also be combined with other data sources for achieving greater insight. For example, if the organizations combine social media information with their specific programs or strategies, these data can reveal whether individuals are potentially interested in a new technology (e.g. blockchain), thus allowing the same organizations to estimate future purchasing patterns. Moreover, the sentiment analysis is a useful tool for measuring users' perceptions and attitudes toward new technologies in tourism. The same considerations can be drawn for any other sector in which innovative technologies are developed and implemented. Starting from the assumption that social media discourse on Twitter represents a proxy to measure the level of diffusion of new technologies, the study highlights how the diffusion of information about new technologies is influenced by the interaction and behaviour of individuals within the same social system. 
Finally, a marginal contribution is also provided from a methodological point of view with the combination between SNA and social media data, which represents a promising methodology in social sciences and, in particular, in the studies on information networks.

\section{Notes}

1. https:/www.forbes.com/sites/danielnewman/2018/01/02/top-6-digital-transformation-trends-in-hospitalityand-tourism/\#2da90e7a67df

2. https://investor.twitterinc.com/financial-information/quarterly-results/default.aspx

3. It has been chosen to use also the keyword \#bitcoin as it represents the first and still most known application/service of blockchain technologies.

\section{References}

Aggarwal, C.C. (2011), "An introduction to social network data analytics", Social Network Data Analytics, Springer, Boston, MA, pp. 1-15.

Araujo, T., Neijens, P. and Vliegenthart, R. (2017), "Getting the word out on twitter: the role of influentials, information brokers and strong ties in building word-of-mouth for brands", International Journal of Advertising, Vol. 36 No. 3, pp. 496-513.

Arenas, A., Goh, J. and Urueña, A. (2019), "How does IT affect design centricity approaches: evidence from Spain's smart tourism ecosystem", International Journal of Information Management, Vol. 45, pp. 149-162.

Arthur, W.B. (1989), "Competing technologies, increasing returns, and lock-in by historical events", The Economic Journal, Vol. 99 No. 394, pp. 116-131.

Asur, S. and Huberman, B.A. (2010), Predicting the future with social media, IEEE/WIC/ACM international conference on web intelligence and intelligent agent technology, Toronto, ON, pp. 492-499.

Bae, Y. and Lee, H. (2012), "Sentiment analysis of twitter audiences: measuring the positive or negative influence of popular twitterers", Journal of the American Society for Information Science and Technology, Vol. 63 No. 12, pp. 2521-2535.

Bandura, A. (1986), "The explanatory and predictive scope of self-efficacy theory", Journal of Social and Clinical Psychology, Vol. 4 No. 3, pp. 359-373.

Bass, F.M. (1969), “A new product growth for model consumer durables”, Management Science, Vol. 15 No. 5, pp. 215-227.

Bian, J., Yoshigoe, K., Hicks, A., Yuan, J., He, Z., Xie, M., Guo, Y., Prosperi, M., Salloum, R. and Modave, F. (2016), "Mining twitter to assess the public perception of the "internet of things", PloS One, Vol. 11, p. 7.

Bolici, F. and Giustiniano, L. (2013), "Design science and eTrust: designing organizational artifacts as nexus of social and technical interactions", Organizational Change and Information Systems, Springer, Berlin, Heidelberg, pp. 177-190.

Bollen, J., Mao, H. and Zeng, X. (2011), "Twitter mood predicts the stock market", Journal of Computational Science, Vol. 2 No. 1, pp. 1-8.

Bonchi, F., Castillo, C., Gionis, A. and Jaimes, A. (2011), "Social network analysis and mining for business applications", ACM Transactions on Intelligent Systems and Technology, Vol. 2, p. 3.

Boucher, P., Nascimento, S. and Kritikos, M. (2017), "How blockchain technology could change our lives", European Parliamentary Research Service, Scientific Foresight Unit, European Parliament, Brussels, pp. 1-28.

Buhalis, D. (1998), "Strategic use of information technologies in the tourism industry", Tourism Management, Vol. 19 No. 5, pp. 409-421. 
Buhalis, D. and Law, R. (2008), "Progress in information technology and tourism management: 20 years on and 10 years after the Internet-the state of eTourism research", Tourism Management, Vol. 29 No. 4, pp. 609-623.

Buhalis, D. and O'Connor, P. (2005), "Information communication technology revolutionizing tourism", Tourism Recreation Research, Vol. 30 No. 3, pp. 7-16.

Buhalis, D. and Sinarta, Y. (2019), "Real-time co-creation and nowness service: lessons from tourism and hospitality", Journal of Travel and Tourism Marketing, Vol. 36 No. 5, pp. 563-582.

Burt, R.S. (1992), Structural Holes: The Social Structure of Competition, University of Illinois at Urbana-Champaign's Academy for Entrepreneurial Leadership Historical Research Reference in Entrepreneurship, Harvard Univ. Press, Cambridge, MA.

Burt, R.S. (2004), "Structural holes and good ideas", American Journal of Sociology, Vol. 110 No. 2, pp. 349-399.

Cabiddu, F., Lui, T. and Piccoli, G. (2013), "Managing value Co-creation in the tourism industry", Annals of Tourism Research, Vol. 42, pp. 86-107.

Capriello, A. and Riboldazzi, S. (2019), "How can a travel agency network survive in the wake of digitalization? Evidence from the Robintur case study", Current Issues in Tourism, Vol. 23, pp. 1-4.

Carillo, K. (2012), "Understanding is theory: an interpretation of key is theoretical frameworks using social cognitive theory", Information Systems Theory, Springer, New York, NY, pp. 241-280.

Chan, S.C. and Lu, M.T. (2004), "Understanding internet banking adoption and use behavior: a Hong Kong perspective", Journal of Global Information Management (JGIM), Vol. 12 No. 3, pp. 21-43.

Chen, L., Gillenson, L. and Sherrell, L. (2002), "Enticing online consumers: an extended technology acceptance perspective", Information and Management, Vol. 39 No. 8, pp. 709-719.

Cheong, F. and Cheong, C. (2011), "Social media data mining: a social network analysis of tweets during the 2010-2011 Australian floods", PACIS, Vol. 11, p. 46.

Colombo, E. and Baggio, R. (2017), Tourism distribution channels: knowledge requirements. In N. Scott, M. De Martino \& M. Van Niekerk (Eds), Knowledge transfer to and within tourism: academic, industry and government bridges, Emerald, Bingley, pp. 289-301.

Cong, L.W. and He, Z. (2019), "Blockchain disruption and smart contracts", Review of Financial Studies, Vol. 32, pp. 1754-1797.

Cravens, D.W., Holland, C.W., Lamb, C.W. Jr and Moncrief, W.C. III (1988), "Marketing's role in product and service quality”, Industrial Marketing Management, Vol. 17 No. 4, pp. 285-304.

Czarnitski, D. and Spielkamp, A. (2003), "Business services in Germany: bridges for innovation", The Service Industries Journal, Vol. 23 No. 2, pp. 1-30.

Dredge, D., Phi, G., Mahadevan, R., Meehan, E. and Popescu, E.S. (2018), Digitalisation in Tourism: InDepth Analysis of Challenges and Opportunities. Low Value Procedure GRO-SME-17-C-091-A for Executive Agency for Small and Medium-Sized Enterprises (EASME) Virtual Tourism Observatory, Aalborg University, Copenhagen.

Egger, R. and Buhalis, D. (Eds). (2011), Etourism case studies, Routledge, Oxford.

Evans, P. and Wurster, T.S. (1999), "Getting real about virtual commerce", Harvard Business Review, Vol. 77, pp. 84-98.

Fan, W. and Gordon, M.D. (2014), "The power of social media analytics", Communications of the ACM, Vol. 57 No. 6, pp. $74-81$.

Femenia-Serra, F., Perles-Ribes, J. and Ivars-Baidal, J. (2019), "Smart destinations and tech-savvy millennial tourists: hype versus reality", Tourism Review, Vol. 74 No. 1, pp. 63-81.

Garcia, A., Linaza, M., Gutierrez, A. and Garcia, E. (2019), "Gamified mobile experiences: smart technologies for tourism destinations", Tourism Review, Vol. 74 No. 1, pp. 30-49.

Goldman Sachs (2014), “All about bitcoin”, Goldman Sachs Global Macro Research, New York, NY. 
Gould, R.V. and Fernandez, R.M. (1989), "Structures of mediation: a formal approach to brokerage in transaction networks", Sociological Methodology, Vol. 19, pp. 89-126.

Gretzel, U. (2011), "Intelligent systems in tourism", Annals of Tourism Research, Vol. 38 No. 3, pp. 757-779.

Gretzel, U., Sigala, M., Xiang, Z. and Koo, C. (2015), "Smart tourism: foundations and developments", Electronic Markets, Vol. 25 No. 3, pp. 179-188.

Grover, P., Kar, A. and Janssen, M. (2019), "Diffusion of blockchain technology", Journal of Enterprise Information Management, Vol. 32 No. 5, pp. 735-757.

Hargadon, A. (1998), "Firms as knowledge brokers: lessons in pursuing continuous innovation", California Management Review, Vol. 40 No. 3, pp. 209-227.

Hargadon, A. (2003), How Breakthroughs Happen: The Surprising Truth about How Companies Innovate, Harvard Business Press, Cambridge, MA.

Hargadon, A. and Sutton, R.I. (1997), "Technology brokering and innovation in a product development firm”, Administrative Science Quarterly, Vol. 42, pp. 716-749.

Haythornthwaite, C. (1996), "Social network analysis: an approach and technique for the study of information exchange", Library and Information Science Research, Vol. 18 No. 4, pp. 323-342.

Howells, J. (2006), "Intermediation and the role of intermediaries in innovation", Research Policy, Vol. 35 No. 5, pp. 715-728.

Ibrahim, N.F. and Wang, X. (2019), "Decoding the sentiment dynamics of online retailing customers: time series analysis of social media", Computers in Human Behavior, Vol. 96, pp. 32-45.

Jeon, H., Ali, F. and Lee, S. (2018), "Determinants of consumers' intentions to use smartphones apps for flight ticket bookings", The Service Industries Journal, Vol. 39 Nos 5-6, pp. 385-402.

Jolliffe, I. (1986), Principal Component Analysis, Springer, New York, NY.

Jörgens, H., Kolleck, N. and Saerbeck, B. (2016), "Exploring the hidden influence of international treaty secretariats: using social network analysis to analyse the Twitter debate on the 'Lima Work Programme on Gender”, Journal of European Public Policy, Vol. 23 No. 7, pp. 979-998.

Kane, G.C. (2017), "The evolutionary implications of social media for organizational knowledge management", Information and Organization, Vol. 27 No. 1, pp. 37-46.

Karahanna, E., Straub, D.W. and Chervany, N.L. (1999), "Information technology adoption across time: a cross-sectional comparison of pre-adoption and post-adoption beliefs", MIS Quarterly, Vol. 23, pp. 183-213.

Karinsalo, A. and Halunen, K. (2018), "Smart contracts for a mobility-as-a-service ecosystem”, 2018 IEEE International Conference on Software Quality, Reliability and Security Companion (QRS-C), IEEE, Lisbon, pp. 135-138.

Kassarjian, H.H. (1977), "Content analysis in consumer research", Journal of Consumer Research, Vol. 4 No. 1, pp. 8-18.

Katona, Z., Zubcsek, P.P. and Sarvary, M. (2011), "Network effects and personal influences: the diffusion of an online social network", Journal of Marketing Research, Vol. 48 No. 3, pp. 425-443.

Khan, M.S., Woo, M., Nam, K. and Chathoth, P.K. (2017), "Smart city and smart tourism: a case of Dubai", Sustainability, Vol. 9 No. 2, p. 2279.

Kwok, A. and Koh, S. (2018), "Is blockchain technology a watershed for tourism development?", Current Issues in Tourism, Vol. 22 No. 20, pp. 2447-2452.

LaRose, R. and Eastin, M.S. (2004), "A social cognitive theory of Internet uses and gratifications: toward a new model of media attendance", Journal of Broadcasting \& Electronic Media, Vol. 48 No. 3, pp. 358-377.

Leung, D. and Dickinger, A. (2017), "Use of bitcoin in online travel product shopping: the European perspective”, in Schegg, R. and Stangl, B. (Eds), Information and Communication Technologies in Tourism, Springer, Cham. 
Lischke, M. and Fabian, B. (2016), “Analyzing the bitcoin network: the first four years", Future Internet, Vol. 8 No. 1, p. 7.

Lyytinen, K. and Damsgaard, J. (2001), “April. What's wrong with the diffusion of innovation theory?”, Working Conference on Diffusing Software Product and Process Innovations, Springer, Boston, MA, pp. 173-190.

Marchegiani, L. and Rossi, G. (2016), Technology applied to the cultural heritage sector has not (yet) exceeded our humanity. In Organizational Innovation and Change, Springer, Cham, pp. 53-62.

McCormick, M.J. and Martinko, M.J. (2004), "Identifying leader social cognitions: integrating the causal reasoning perspective into social cognitive theory", Journal of Leadership and Organizational Studies, Vol. 10 No. 4, pp. 2-11.

McDougall, G.H. and Levesque, T. (2000), "Customer satisfaction with services: putting perceived value into the equation", Journal of Services Marketing, Vol. 14, pp. 392-410.

Meriläinen, K. (2017), "From floating to leading: the transformation of digital marketing capabilities through ICT uptake in tourism SMEs", Schegg, R. and Stangl, B. (Eds), Information and Communication Technologies in Tourism 2017, Springer, Cham.

Middleton, V.T.C., Fyall, A., Morgan, M. and Ranchhod, A. (2009), Marketing in travel and tourism, Routledge, Oxford.

Millar, C.C.J.M. and Choi, C.J. (2003), "Advertising and knowledge intermediaries: managing the ethical challenges of intangibles", Journal of Business Ethics, Vol. 48 No. 3, pp. 267-277.

Min, W. (2008), Research on Intelligent Systems Applied to Tourism Development Design, 2008 Eighth International Conference on Intelligent Systems Design and Applications, IEEE, Kaohsiung, pp. 127-132.

Min, S., So, K. and Jeong, M. (2018), "Consumer adoption of the Uber mobile application: insights from diffusion of innovation theory and technology acceptance model", Journal of Travel and Tourism Marketing, Vol. 36 No. 7, pp. 770-783.

Monroe, K.B. (1990), Pricing - Making Profitable Decisions, McGraw-Hill, New York, NY.

Nam, K., Dutt, C.S., Chathoth, P. and Khan, M.S. (2019), "Blockchain technology for smart city and smart tourism: latest trends and challenges", Asia Pacific Journal of Tourism Research.

Nasukawa, T. and Yi, J. (2003), Sentiment analysis: capturing favorability using natural language processing, Proceedings of the 2nd international conference on Knowledge capture, Florida, 2325, pp. $70-77$.

Neuhofer, B., Buhalis, D. and Ladkin, A. (2013), "A typology of technology-enhanced tourism experiences", International Journal of Tourism Research, Vol. 16 No. 4, pp. 340-350.

Nofer, M., Gomber, P., Hinz, O. and Schiereck, D. (2017), "Blockchain", Business and Information Systems Engineering, Vol. 59, pp. 183-187.

O'Connor, B., Balasubramanyan, R., Routledge, B.R. and Smith, N.A. (2010), From tweets to polls: linking text sentiment to public opinion time series, Proceedings of the International AAAI conference on weblogs and social media, Washington, DC, pp. 122-129.

Omar, N., Musa, R. and Nazri, M. (2007), "Program perceived value and program satisfaction influences on store loyalty: insights from retail loyalty program”, Gadjah Mada International Journal of Business, Vol. 9 No. 3, p. 355.

Pang, B. and Lee, L. (2008), "Opinion mining and sentiment analysis", Foundations and Trends ${ }^{\circledR}$ in Information Retrieval, Vol. 2 No. 1-2, pp. 1-135.

Polasik, M., Piotrowska, A., Wisniewski, T., Kotkowski, R. and Lightfoot, G. (2014), "Price fluctuations and the use of bitcoin: an empirical inquiry", SSRN Electronic Journal, Vol. 20, pp. 9-49.

Porter, M.E. (1990), The Competitive Advantage of Nations: With a New Introduction, Free Press.

Presenza, A., Messeni Petruzzelli, A. and Sheehan, L. (2019), "Innovation through tradition in hospitality. The Italian case of Albergo Diffuso", Tourism Management, Vol. 72, pp. 192-201.
Innovation diffusion in tourism 
Ratten, V. and Ratten, H. (2007), "Social cognitive theory in technological innovations", European Journal of Innovation Management, Vol. 10, pp. 90-108.

Rogers, E.M. (2003), Diffusion of Innovations, 5th ed., Free Press, New York, NY.

Rueda-Esteban, N. (2018), "Technology as a tool to rebuild heritage sites: the second life of the Abbey of Cluny”, Journal of Heritage Tourism, Vol. 14 No. 2, pp. 101-116.

Saberi, S., Kouhizadeh, M., Sarkis, J. and Shen, L. (2019), "Blockchain technology and its relationships to sustainable supply chain management", International Journal of Production Research, Vol. 57 No. 7, pp. 2117-2135.

Sheth, J.N., Newman, B.I. and Gross, B.L. (1991), Consumption Values and Market Choices: Theory and Applications, South-Western Pub, Cincinnati, OH, pp. 16-74.

Sproull, L. and Kiesler, S. (1991), “Computers, networks and work”, Scientific American, Vol. 265 No. 3, pp. 116-127.

Staab, S., Werthner, H., Ricci, F., Zipf, A., Gretzel, U., Fesenmaier, D.R., Paris, C. and Knoblock, C. (2002), "Intelligent systems for tourism", IEEE Intelligent Systems, Vol. 17 No. 6, pp. 53-64.

Stamboulis, Y. and Skayannis, P. (2003), "Innovation strategies and technology for experience-based tourism", Tourism Management, Vol. 24 No. 1, pp. 35-43.

Stankov, U. and Filimonau, V. (2018), "Reviving calm technology in the e-tourism context", The Service Industries Journal, Vol. 39 Nos 5-6, pp. 343-360.

Statista (2019), e Travel Report 2019.

Statista (2020), Number of Blockchain Wallet Users Worldwide from 3rd Quarter 2016 to 4th Quarter 2019.

Stovel, K. and Shaw, L. (2012), "Brokerage”, Annual Review of Sociology, Vol. 38, pp. 139-158.

Swacha, J. (2019), "Architecture of a dispersed gamification system for tourist attractions", Information, Vol. 10 No. 1, p. 33.

Sweeney, J.C. and Soutar, G.N. (2001), "Consumer perceived value: the development of a multiple item scale”, Journal of Retailing, Vol. 77 No. 2, pp. 203-220.

Taboada, M., Brooke, J., Tofiloski, M., Voll, K. and Stede, M. (2011), "Lexicon-based methods for sentiment analysis", Computational Iinguistics, Vol. 37 No. 2, pp. 267-307.

Thelwall, M., Buckley, K. and Paltoglou, G. (2011), "Sentiment in twitter events", Journal of the American Society for Information Science and Technology, Vol. 62 No. 2, pp. 406-418.

Treiblmaier, H., Önder, I. (2019), The impact of blockchain on the tourism industry: a theory-based research framework. in: Treiblmaier, H., Beck, R. (Eds) Business Transformation through Blockchain, Palgrave Macmillan, Cham.

Troshani, I. and Doolin, B. (2007), "Innovation diffusion: a stakeholder and social network view", European Journal of Innovation Management, Vol. 10 No. 2, pp. 176-200.

Tzeng, G.H. and Huang, J.J. (2011), Multiple Attribute Decision Making: Methods and Applications, Chapman and Hall/CRC, New York.

Van Dijk, J. (2012), The Network Society, Sage Publications, CA.

Venkatesh, V., Morris, M.G., Davis, G.B. and Davis, F.D. (2003), "User acceptance of information technology: toward a unified view", MIS Quarterly, pp. 425-478.

Wang, W., Liu, L., Feng, Y. and Wang, T. (2014), "Innovation with IS usage: individual absorptive capacity as a mediator", Industrial Management \& Data Systems, Vol. 114 No. 8, pp. 1110-1130.

Wasserman, S. and Faust, K. (1994), Social Network Analysis: Methods and Applications, Cambridge University Press, Cambridge, Vol. 8.

Werthner, H. (2003), "Intelligent systems in travel and tourism", IJCAI'O3 Proceedings of the 18th International Joint Conference on Artificial intelligence, Morgan Kaufmann Publishers, San Francisco, CA, pp. 1620-1625. 
Williams, H.T.P., McMurray, J.R., Kurz, T. and Lambert, F.H. (2015), "Network analysis reveals open forums and echo chambers in social media discussions of climate change", Global Environmental Change, Vol. 32, pp. 126-138.

Winch, G.M. and Courtney, R. (2007), "The organization of innovation brokers: an international review”, Technology Analysis \& Strategic Management, Vol. 19 No. 6, pp. 747-763.

Wood, R. and Bandura, A. (1989), "Social cognitive theory of organizational management", Academy of Management Review, Vol. 14 No. 3, pp. 361-384.

Xiang, Z., Magnini, V. and Fesenmaier, D. (2015), "Information technology and consumer behavior in travel and tourism: insights from travel planning using the internet", Journal of Retailing and Consumer Services, Vol. 22, pp. 244-249.

Zhang, S., Li, Y., Liu, C. and Ruan, W. (2019), "Critical factors in the identification of word-of-mouth enhanced with travel apps: the moderating roles of Confucian culture and the switching cost view", Asia Pacific Journal of Tourism Research, Vol. 24 No. 5, pp. 422-442.

\section{Further reading}

Treiblmaier, H. and Beck, R. (n.d.), Business Transformation through Blockchain.

\section{About the authors}

Francesco Bolici is an associate professor of Organizational Design and Management of Information Systems at Cassino University (Italy), Scientific Director of OrgLab - Laboratory of Organization Studies. PhD in Management of Information Systems at LUISS Guido Carli University. Marie Curie Fellow (European Commission program) at Uppsala University (Sweden). He has been: Visiting Scholar at School of Information Studies, Syracuse University (USA); Visiting and Affiliate Professor at IESEG Business School (France) for 13 years. He has been nominated independent expert for several European calls and research projects (FP7, H2020). Research areas: innovative coordination and communication models enabled by information technology; organization design in complex systems.

Chiara Acciarini is a PhD Student in Management at LUISS Guido Carli University - Rome, Italy where she also held cum laude the Master's Degree in Management. She is Research Fellow for the Research Centre for Business Transformation (ReBoot), LUISS Business School and Teaching Assistant to Corporate Strategies for Master's Courses, LUISS Guido Carli. She also supports the Global Family Business Management Executive Programme, Luiss Business School and the Management and Governance of Family Firms Masters' Course, Luiss Guido Carli. Her research is focused on the impact of specific board's determinants - e.g. digital expertise - on the strategic change of the firms. Chiara Acciarini is the corresponding author and can be contacted at: cacciarini@luiss.it

Lucia Marchegiani is an associate professor of Business Organization and Human Resources Management at Roma Tre University. She holds a PhD in Organization and Information Systems. Her research interests cover topics such as Technology and Organizations, Knowledge Management, Creative and Cultural Industries, Agile Work and Sustainability. She has been visiting scholar at the Copenhagen Business School (DK), IESEG Business School (F), University of Copenhagen (DK) and ISC Business School at Paris (F). As Project manager of several research projects, she has developed leadership skills and project management capabilities. As a happy mom of six kids, she has developed a multitasking approach and an attitude for care, mediation and negotiation.

Luca Pirolo, $\mathrm{PhD}$ in Management, is an assistant professor at Luiss Guido Carli University in Rome where he teaches "Management" and "Creative Industries and Business Model Innovation". At Luiss Business School level, he is the Director of Luiss Creative Business Centre, an active competence centre created to investigate on the management of creativity, and he is the director of some master programs (Master of Art, Master in Media Entertainment Business and Master of Fashion and Luxury Management). His research activities on creative and cultural industries range from project-based organization, performance measurement and knowledge management.

For instructions on how to order reprints of this article, please visit our website:

www.emeraldgrouppublishing.com/licensing/reprints.htm

Or contact us for further details: permissions@emeraldinsight.com 